M.D. Bedder MD, R. Kozody MD FRCPC, R.J. Palahniuk MD FRCPC, M.O. Cumming RN B SC, W.R. Pucci

\title{
Clonidine prolongs canine tetracaine spinal anaesthesia
}

Using a randomized blind cross-over design, the comparative efficacy of clonidine in prolonging tetracaine spinal anaesthesia was studied in six mongrel dogs.

Lumbar subarachnoid injections ( $1 \mathrm{ml}$ ) of: tetracaine $4 \mathrm{mg}$ with clonidine $150 \mathrm{\mu g}$, tetracaine $4 \mathrm{mg}$ with epinephrine $200 \mu \mathrm{g}$, tetracaine $4 \mathrm{mg}$, clonidine $150 \mu \mathrm{g}$, epinephrine $200 \mu \mathrm{g}$, and five per cent dextrose in $\mathrm{H}_{2} \mathrm{O}$ (vehicle) were administered randomly to each animal at 5-7 day intervals.

Subarachnoid tetracaine produced a motor blockade of $186 \pm 58$ (mean \pm SEM) min. Both clonidine and epinephrine produced a similar prolongation of tetracaine motor blockade, 135 per cent $(p<0.01)$ and 116 per cent $(p<0.05)$ respectively, compared with tetracaine alone. No motor blockade was observed in dogs receiving clonidine, epinephrine or five per cent dextrose in $\mathrm{H}_{2} \mathrm{O}$. The addition of clonidine to tetracaine spinal anaesthesia produced a significant increase in duration of sensory blockade, 56 per cent $(p<0.01)$ and 107 per cent $(p<$ $0.01)$ respectively, when compared to tetracaine with and without epinephrine. Subarachnoid clonidine alone produced a sensory blockade of $76 \pm 17$ minutes, while only one animal receiving subarachnoid epinephrine had a sensory blockade (40 minutes). No neurologic deficits were observed in any of the animals.

The study concludes that during spinal anaesthesia with tetracaine in dogs, clonidine is as effective as epinephrine in prolonging motor blockade, but is more effective in prolonging sensory blockade.

\section{Key words}

ANAESTHETIC TECHNIQUES: subarachnoid block; ANAESTHETICS, LOCAL: tetracaine; SYMPATHETIC NERVOUS SYSTEM, CATECHOLAMINES: epinephrine; ADRENOCEPTOR AGONIST: clonidine.

From the Department of Anaesthesia, University of Manitoba, Winnipeg, Manitoba.

Address correspondence to: Dr. R. Kozody, Department of Anesthesia, University of Manitoba,

LB315-60 Pearl Street, Winnipeg, Manitoba, R3E 1X2.

Supported by a grant from the University of Manitoba Faculty Fund.
Spinal anaesthesia was introduced by August Bier in 1898 and vasoconstrictors were first introduced to prolong spinal anaesthesia by Braun in 1900 .' Bier $^{2}$ and Heinke and Lawen, ${ }^{3}$ among others, used epinephrine intrathecally with cocaine in order to prolong the duration of spinal anaesthesia.

Since the initial introduction, the use of vasoconstrictors to prolong spinal anaesthesia has caused controversy among anaesthetists. Bonica et al. ${ }^{4}$ found that phenylephrine and epinephrine both increased the duration of motor and sensory blockade by 50 per cent, while the effects of ephedrine were much less pronounced. Moore and Bridenbaugh $^{5}$ looked at 8,852 patients who had vasoconstrictor drugs injected into the subarachnoid space along with the local anaesthetic solution. In their study epinephrine extended the duration of anaesthesia by 50 per cent compared with 100 per cent for phenylephrine. A recent study by Feldman and Covino $^{6}$ examined the effect of vasoconstrictor agents in prolonging the duration of spinal anaesthesia in the dog. Their results showed a 58 per cent increase in duration of motor blockade following subarachnoid administration of tetracaine with epinephrine and a 22.5 per cent increase using phenylephrine when compared with a control solution of plain tetracaine.

Kozody et al. ${ }^{7,8}$ proposed a hypothesis to explain why epinephrine and phenylephrine prolong the duration of clinically useful tetracaine but not lidocaine or bupivacaine spinal anaesthesia. ${ }^{9,10}$ They suggested that a vasopressor mediated inhibition of local anaesthetic-induced regional spinal cord and dural arteriolar vasodilation may be partially responsible for the prolonged duration of tetracaine spinal anaesthesia when epinephrine is used as an adjunct. Vasoconstrictors are believed to affect the absorption of various local anaesthetics to varying degrees depending on the intrinsic vasodilatory activity and lipid solubility of the agent 
used. Pharmacologically decreased absorption produces a prolonged regional effect. ${ }^{7}$

Animal studies have demonstrated that the intrathecal injection of alpha-receptor agonists produce analgesia which depending on the agonist, may be comparable to opiate-induced analgesia. ${ }^{11}$ Clonidine, a predominantly alpha $a_{2}$ adrenoceptor agonist with some alpha ${ }_{1}$ stimulating properties, has been shown to have a marked analgetic effect when administered intrathecally. ${ }^{12,13}$ Following parenteral clonidine administration, vasoconstriction occurs predominantly via postsynaptic alpha ${ }_{2}$ adrenoceptor stimulation. ${ }^{14}$ Theoretically the pharmacodynamic properties of clonidine would make it a useful adjunct to spinal anaesthesia based on the two proposed mechanisms. The present study was therefore undertaken to assess the comparative efficacy of clonidine and epinephrine in prolonging tetracaine spinal anaesthesia in dogs.

\section{Methods}

Guidelines for the humane treatment of laboratory animals as outlined by the Canadian Council on Animal Care were followed. Six mongrel dogs of either sex weighing $17 \mathrm{~kg}$ were studied using a randomized blind cross-over design. Following induction of anaesthesia (intravenous thiopentone $15-30 \mathrm{mg} \cdot \mathrm{kg}^{-1}$ ) and tracheal intubation, the animals were placed on an operating table in the right lateral decubitus position with a $10^{\circ}$ head-up table tilt. Anaesthesia was maintained with $\mathrm{N}_{2} \mathrm{O}: \mathrm{O}_{2}(2: 1)$ and isoflurane (1.5-2 per cent). The low back region $\left(L_{1}-S_{1}\right)$ was shaved and the skin prepared with povidone iodine. The lumbar region was draped and a lumbar puncture was attempted with a 22 gauge $3 \frac{1}{2}$-inch spinal needle at the $L_{6}-L_{7}$ interspace. If this was unsucessful a repeat attempt was performed at the $\mathrm{L}_{5}-\mathrm{L}_{6}$ interspace. Successful dural puncture was confirmed by the free flow of one to two drops of CSF from the needle hub.

Each animal received the following solutions in $1 \mathrm{ml} \mathrm{D5} / \mathrm{W}$ in a randomized order at five- to seven-day intervals: tetracaine $4 \mathrm{mg}$, tetracaine $4 \mathrm{mg}$ with clonidine $150 \mu \mathrm{g}$, tetracaine $4 \mathrm{mg}$ with epinephrine $200 \mu \mathrm{g}$, clonidine $150 \mu \mathrm{g}$, epinephrine $200 \mu \mathrm{g}$ or five per cent dextrose $\mathrm{H}_{2} \mathrm{O}$ (vehicle). Following completion of the subarachnoid injection, anaesthesia was discontinued and the animals were allowed to recover in the right lateral decubitus position.
Time from intrathecal injection to arousal was recorded for each animal and on awakening the endotracheal tube was removed. Following arousal the animals were assessed for motor and sensory blockade at 20-minute intervals for one hour and at 15 -minute intervals thereafter. The end point for recovery of motor function was the ability of the animal to stand unsupported on its hind limbs.

Sensory blockade was assessed using a modified method of Eger $e t$ al. ${ }^{15}$ A ten-inch rubber shod haemostat was applied (first rachet) longitudinally to the proximal one third of the shaved tail. The haemostat was moved continuously for a 60 second application or until an avoidance response was elicited. A reproducible avoidance response was interpreted as a return of sensation. All assessments of motor and sensory blockade were performed by an observer unaware of the drug administered. Following regression of motor and sensory blockade the animals were returned to the central animal boarding facilities and observed for a five- to sevenday period.

The data were analyzed using a one way analysis of variance with post-ANOVA multiple comparisons being performed, using Duncan's Test. A value of $p<0.05$ was considered statistically significant.

\section{Results}

The time from subarachnoid injection to arousal was $19 \pm 2$ (mean $\pm S E M$ ) minutes. Although a tendency for prolonged somnolence was observed in animals receiving subarachnoid tetracaine with clonidine and clonidine alone, no significant difference was observed between the groups (Figure 1). One dog in the clonidine group was eliminated from the study, because of prolonged time to arousal (>90 min) and inability to assess sensory function. The prolonged time to arousal was the result of increased anaesthetic induction requirement necessitating a total dose of thiopentone exceeding $40 \mathrm{mg} \cdot \mathrm{kg}^{-1}$.

Subarachnoid tetracaine produced a hindlimb motor blockade of $186 \pm 58 \mathrm{~min}$ (Figure 2). The addition of clonidine and epinephrine to the tetracaine solution produced a similar significant prolongation of motor blockade, $438 \pm 37 \mathrm{~min}$ and $402 \pm$ 63 min respectively. The values represent a 135 per cent $(p<0.01)$ and 116 per cent $(p<0.05)$ respective increase in motor blockade duration when 


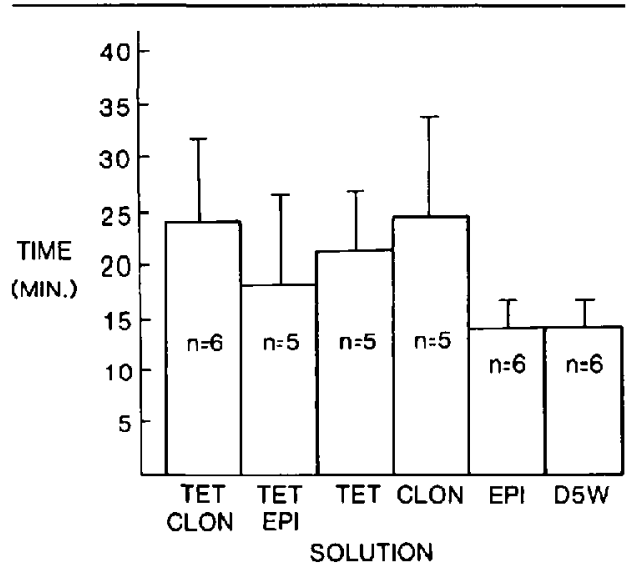

FIGURE 1 Time to arousal. TET CLON: tetracaine $4 \mathrm{mg}$ with clonidine $150 \mu \mathrm{g}$. TET EPI: tetracaine $4 \mathrm{mg}$ with epinephrine $200 \mu \mathrm{g}$. TET: tetracaine $4 \mathrm{mg}$, CLON: clonidine $150 \mu \mathrm{g}$, EPI: epinephrine $200 \mu \mathrm{g}$, DSW: $5 \%$ dextrose $\mathrm{H}_{2} \mathrm{O}$ (vehicle). No significant difference.

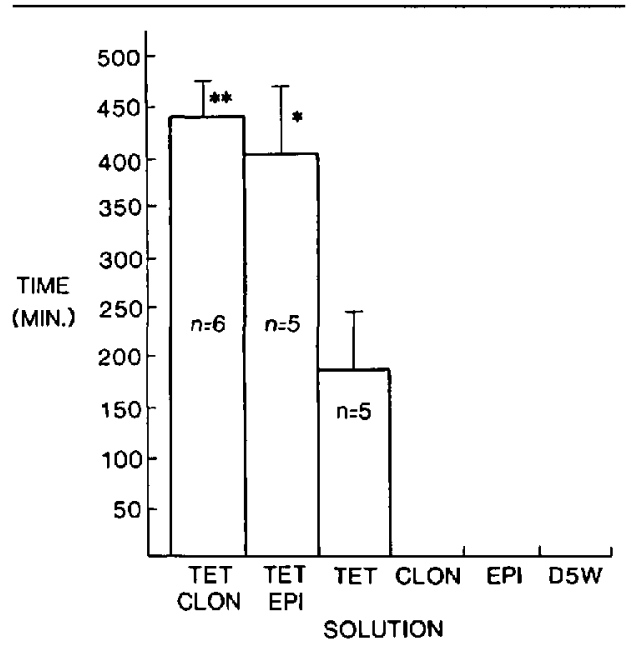

FIGURE 2 Duration of motor blockade. (Abbreviations as in Figure 1). Results expressed as mean \pm SEM. ${ }^{*} \mathrm{p}<0.05$. ** $p<0.01$ compared with tetracaine plain.

compared with the plain tetracaine solution. One animal was eliminated from each of the tetracaine and tetracaine with epinephrine groups because of the absence of motor blockade on arousal. No hindlimb motor blockade was observed in dogs receiving clonidine, epinephrine or D5/W. In dogs

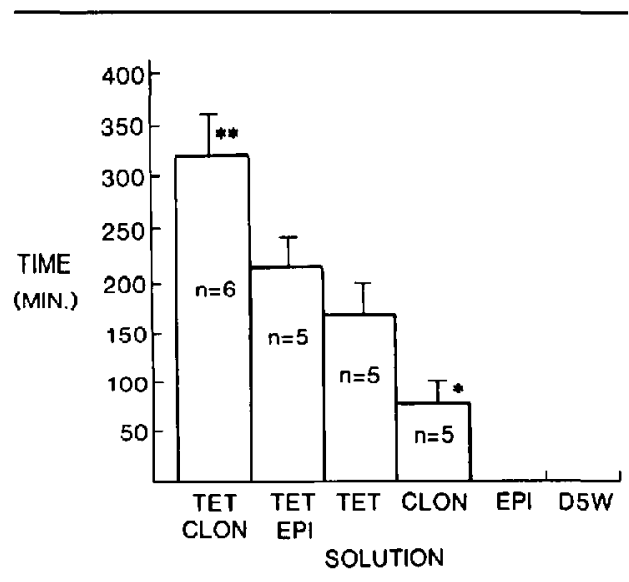

FIGURE 3 Duration of sensory blockade. (Abbreviations as in Figure 1). Results expressed as mean \pm SEM. ${ }^{*} p<0.05$. **p $<0.01$ compared with tetracaine plain.

receiving subarachnoid clonidine a temporary jumping hindlimb gait was observed in four of the five dogs. The remaining animal, an elderly dog with a lethargic gait demonstrated a temporary improvement in gait, which became similar to that observed in healthy young dogs.

Subarachnoid tetracaine produced a sensory blockade of $156 \pm 23$ minutes (Figure 3). The addition of epinephrine to tetracaine spinal anaesthesia produced a non-significant prolongation of sensory blockade ( $207 \pm 23 \mathrm{~min}$ ). Clonidine when added to tetracaine spinal anaesthesia produced a significant increase in duration of sensory blockade $(323 \pm 31 \mathrm{~min}$ ) compared with tetracaine alone or tetracaine with epinephrine. The respective increases were 107 per cent $(p<0.01)$ and 56 per cent $(p<0.01)$. Subarachnoid clonidine alone produced a sensory blockade of $76 \pm 17$ minutes. One animal receiving subarachnoid epinephrine alone had a sensory blockade of $\mathbf{4 0}$ minutes, while no animals receiving subarachnoid five per cent dextrose in $\mathrm{H}_{2} \mathrm{O}$ had sensory blockade.

Gross neurologic assessment of the animals between injections and at the completion of the study was normal.

\section{Discussion}

A recurrent problem with studies comparing the duration of motor and especially sensory blockade following spinal anaesthesia is the lack of stan- 
dardization of assessment. Duration has been assessed in a number of differing ways including: time to two-segment or four-segment regression of analgesia, time to disappearance of adequate operative analgesia, time to regression of motor blockade, or time to first administration of postoperative analgesic. Careful standardization of assessment and the use of a randomized double-blind methodology is necessary for a true comparison. In our study, the method of sensory assessment used would be considered equivalent to time to regression of adequate operative analgesia. The duration of nonoperative "analgesia" although not addressed in the present study, may be prolonged with subarachnoid clonidine, compared with other alpha adrenergic agonists. ${ }^{13}$ The 56 per cent increase in duration of sensory blockade to a surgical stimulus seen with tetracaine plus clonidine versus tetracaine with epinephrine, could offer additional benefits in the form of prolonged postoperative analgesia.

Clonidine may prolong the sensory blockade observed with tetracaine through a spinal cord presynaptic alpha $a_{2}$ adrenoceptor mechanism, a postsynaptic alpha ${ }_{2}$ adrenoceptor arteriolar effect and/ or a supraspinal alpha ${ }_{2}$ antinociceptive action. Nociceptive sensory input has been shown in previous studies to be associated with central and spinal adrenergic neurons. ${ }^{11,12}$ Regions in the rat CNS where alpha $a_{2}$ binding sites are found are innervated by norepinephrine and epinephrine containing neurons. The neurophysiological functions of the various brain regions having high densities of alpha $_{2}$ binding sites correlate with the various pharmacologic effects of clonidine. In a study by Luttinger et al. ${ }^{16}$ subcutaneous clonidine elicited antinociception, and this effect was attenuated by pretreatment with the alpha $a_{2}$ adrenergic antagonist yohimbine.

Since Yaksh et al. demonstrated that spinal cord alpha adrenergic stimulation produces antinociception the relative contribution of alpha $a_{1}$ and alpha adrenoreceptor has been debated. Zemlan et al. ${ }^{17}$ observed a dose-related analgesia using clonidine in the spinal rat which was blocked by pretreatment with the alpha adrenergic receptor blocker phenoxybenzamine. Fleetwood-Walker et al. ${ }^{18}$ demonstrated the presence of specific adrenergic receptors at sites in the dorsal horn that could mediate similar effects from descending noradrenergic systems. The selective effect of nor- adrenaline on inhibiting the responses to noxious cutaneous stimulation of spinocerebellar tract and dorsal column postsynaptic neurones was mimicked by clonidine. Antagonism of the noradrenaline effect by yohimbine confirmed the involvement of an alpha $_{2}$ receptor. The lack of selective effects of the alpha $a_{1}$ and beta agonists phenylephrine and isoprenaline, further supported the conclusion that an alpha ${ }_{2}$ mechanism mediates the noradrenaline effect. It appears that alpha agonists can exert a significant inhibitory effect on spinal presynaptic neurons. ${ }^{19}$ This is substantiated by the recent work of Calvillo and Ghignone ${ }^{20}$ who demonstrated that clonidine caused primary afferent depolarization of intraspinal cutaneous $\mathrm{C}$ fibres, thereby decreasing transmitter release through presynaptic inhibitory mechanisms. These studies support the role of alpha $a_{2}$ adrenoreceptor mechanism in selective inhibition of nociceptive input at the spinal level.

Marwaha et al., ${ }^{19}$ however, caution against ascribing the effects of intrathecal administration of lipophilic drugs like clonidine solely to actions in the spinal cord. They reported that low doses of intrathecally administered clonidine (6-25 $\mu \mathrm{g} \cdot \mathrm{kg}^{-1}$ ) consistently inhibited locus coeruleus neuronal firing. They ascribed this inhibition as secondary to the rapid diffusion of clonidine from the spinal subarachnoid space into the general circulation.

A third possible mechanism of clonidine-induced prolorgation of analgesia is through adrenoreceptor mediated vasoconstriction. Kiowski et al. ${ }^{20}$ suggest that, apart from the classical alpha ${ }_{1}$ adrenoreceptor, there is a second type of adrenergic receptor on smooth muscle cells that can mediate vasoconstriction, resembling the alpha 2 adrenoreceptor pharmacologically and these receptors may mediate vasoconstriction to exogenous catecholamines.

The direct antinociceptive effects of intrathecal alpha agonists, however, are unlikely to be secondary to local ischaemia, as they have been shown to be reliably reversible and unaffected in their action by vasodilator agents. ${ }^{21} \mathrm{~A}$ vasoactive interaction between tetracaine and clonidine much like the interaction described by Kozody et al. with tetracaine and epinephrine, ${ }^{9,10}$ could be responsible for the prolongation of spinal anaesthesia. The prolongation of sensory blockade could also be explained 
by a synergism between the antinociceptive effects of clonidine and the neural blocking actions of tetracaine. However, since clonidine in low doses has little effect on motor function, a synergistic effect between alpha $a_{2}$ adrenoceptor function and tetracaine motor blockade seems unlikely. The likely hypothesis to explain the prolongation of motor blockade appears to be decreased vascular uptake of tetracaine as a consequence of the alpha mediated inhibition of tetracaine-induced vasodilation.

Our study confirms the analgetic properties of intrathecal clonidine. In conjunction with tetracaine, clonidine was superior to epinephrine in prolonging sensory blockade following the single intrathecal dose compared. One animal in the epinephrine group displayed a sensory blockade to a surgical stimulus. This agrees with data from Collins et al. ${ }^{22}$ who reported a significant but incomplete suppression of noxiously evoked activity following $50 \mu \mathrm{g}$ or $100 \mu \mathrm{g}$ doses of subarachnoid epinephrine in cats.

No animal studied had any gross evidence of neurologic sequelae. Coombs et al. ${ }^{23}$ investigated possible neurotoxicity of clonidine in the sheep and concluded that clonidine was not neurotoxic and this is supported by other human and animal studies. ${ }^{13,21,24}$

Administration of clonidine has resulted in "normalization" of sensory-motor and autonomic dysfunctions in the cat following traumatic spinal cord injury. ${ }^{25}$ Preliminary studies of the use of clonidine in humans with traumatically injured spinal cords indicates that autonomic dysfunction can be controlled and spasticity minimized. This effect may be similar to the normalization of gait seen in one of our dogs.

Clonidine as an adjunct in spinal anaesthesia may provide advantages over the established vasoconstrictors, including prolonged duration of blockade, improved cardiovascular stability, ${ }^{26}$ and postoperative analgesia. Further studies are required to assess dose response, haemodynamic, and regional circulatory effects of clonidine.

\section{Acknowledgements}

We would like to express our thanks to Boehringer Ingelheim for supplying clonidine crystals free of charge.

\section{References}

1 Braun $H$. Lokal Anesthesic, ed. 1, Leipsig, JA Barth, 1905. Braun H. Local Anesthesia, ed. 3 (translated by P. shields), p. 143, Philadelphia, 1914, Lea and Febiger.

2 Bier A, Donitz A. Ruckenmarksanasthesie, Munchen med. Wehnschr 1904; 1: 593-6.

3 Heinke $H$, Lawen A. Experimentelle Untersuchungen und Klinische Erfahrungen uber die verwertbarkeit von Novokain fur die Artliche Anasthesie, Deutsche Zschr. f. Chir. 1905; 80: 180-98.

4 Bonica JJ, Backup PH, Pratt WH. The use of vasoconstrictors to prolong spinal anaesthesia. Anesthesiology 1951; 12: 431-41.

5 Moore $D C$, Bridenbaugh $L D$. Spinal (subarachnoid) block. JAMA 1966; 195: 123-8.

6 Feldman $H S$, Covino BG. Effect of vasoconstrictor agents on prolonging the duration of spinal anaesthesia in the dog. Regional Anesthesia 1985; 10: 133-8.

7 Kozody R, Palahniuk RJ, Wade JG, Cumming MO, Pucci WR. The effect of subarachnoid epinephrine and phenylephrine on spinal cord blood flow. Can Anesth Soc J 1984; 31: 503-8.

8 Kozody R, Palahniuk RJ, Cumming MO. Spinal cord blood flow following subarachnoid tetracaine. Can Anesth Soc J 1985; 32: 23-9.

9 Chambers WA, Littlewood DG, Logan MR, Scott $D B$. Effect of added epinephrine on spinal anesthesia with lidocaine. Anesth Analg 1981; 60: 417-20.

10 Chambers WA, Litllewood DG, Scott DB. Spinal anesthesia with hyperberic bupivacaine effect of added vasoconstrictors. Anesth Analg 1982; 61: 49-52.

11 Reddy SV, Ladervt L, Yaksh TL. Spinal cord pharmacology of adrenergic agonist-mediated antinociception. J Pharmacol Exp Ther 1980; 213: 525-33.

12 Reddy SYR, Yaksh TL. Spinal noradrenergic terminal system mediating antinociception. Brain Research 1980; 189: 391-401.

13 Coombs $D W$, Saunders $R L$, Lachance $D$, Savage $S$, Ragnarsson TS, Jensen $L E$. Intrathecal morphine tolerance: use of intrathecal clonidine, DADLE, and intraventricular morphine. Anesthesiology 1985; 62: 358-63.

14 Weiner $N$. Drugs that inhibit adrenergic nerves and block adrenergic receptors in The Pharmacological Basis of Therapeutics. Ed. Gilman AC, Goodman LS, Gilman A, New York. MacMillan Pub Co Inc 1980; Chp. 8: 197-8.

15 Eger EI II, Saidman W, Brandstater B. Minimum 
alveolar anesthetic concentration: a standard of anesthetic potency. Anes. 1965; 26: 756-63.

16 Luttinger D, Ferrari R, Perrone MH, Haubrich DR. Pharmacological analysis of alpha-2 adrenergic mechanisms in nociception and ataxia. J Pharmacol Exp Ther 1985; 232: 883-9.

17 Zemlan FP, Corrigan SA, Pfaff DW. Noradrenergic and serotonergic mediation of spinal analgesia mechanisms. Eur J Pharmacol 1980; 61: 111-24.

18 Fleetwood-Walker SM, Mitchell R, Hope RJ, Molony V, Iggo A. An alpha 2 receptor mediates the selective inhibition by noradrenaline of nociceptive responses of identified dorsal hom neurons. Brain Research 1985; 334: 243-56.

19 Unnerstall JR, Kopajtic TA, Kihar MJ. Distribution of $a_{2}$ agonist binding sites in the rat and human central nervous system: analysis of some functional, anatomic correlates of the pharmacologic effects of clonidine and related adrenergic agents. Brain Research Review 1984; 7: 69-101.

20 Calvillo $O$. Ghignone $M$. Primary afferent depolarization of cutaneous $C$ fibers in the cat spinal cord evoked by clonidine. Fed Proc 1985; 2799: 44.

21 Marwaha J, Kehne JH, Commissaris RL, Lakoski $J$, Shaw W, Davis M. Spinal clonidine inhibits neural firing in locus coeruleus. Brain Research 1983; 276: 379-82.

22 Kiowski W, Hulthen UL, Ritz R, Buhler FR. Alpha 2 adrenoreceptor mediated vasoconstriction of arteries. Clin Pharmacol Ther 1983; 34: 565-9.

23 Yaksh TL, Reddy SVR. Studies in the primate on the analgetic effects associated with intrathecal actions of opiates, alpha adrenergic agonists and baclofen Anesthesiology 1981; 54: 451-67.

24 Collins JG, Kitahata LM, Matsumoto M, Homma E, Suzukawa $M$. Spinally administered epinephrine suppresses noxiously evoked activity of WDR neurons in the dorsal horn of the spinal cord. Anesthesiology 1984; 60: 269-75.

25 Coombs DW, Allen C, Meier FA, Fratkin I Chronic intraspinal clonidine in the sheep. Regional Anesth 1984; 9: 47 (abstract).

26 Tamsen A, Gordh TE. Clonidine is not neurotoxic. Lancet, 1984; 2: 876.

27 Naftchi EN. Functional restoration of the traumatically injured spinal cord in cats by clonidine. Science $1982 ; 217$ : 1042-4.

28 Ghignone M, Quintin L, Duke PC, Kehler CH, Calvillo $O$. Effects of clonidine on narcotic require- ments and hemodynamic response during induction of fentanyl anesthesia and endotracheal intubation. Anesthesiology 1986; 64: 36-42.

\section{Résumé}

Avec une étude à double insu randomisée, l'efficacité comparative de la clonidine dans la prolongation d' une rachi-anesthésie à la tetracaïne a été étudiée avec six chiens bâtards.

Des injections sous-arachnoïdiennes lombaires $(\mathrm{I} \mathrm{ml})$ de: tetracaïne $4 \mathrm{mg}$ avec clonidine $150 \mu \mathrm{g}$, tetracaïne $4 \mathrm{mg}$ avec épinephrine $200 \mu \mathrm{g}$, tetracaïne $4 \mathrm{mg}$, clonidine $150 \mu \mathrm{g}$, épinéphrine $200 \mu \mathrm{g}$, et cinq pour cent dextrose dans l'eau ont été administrées d'une façon randomisée à chaque animal avec un intervalle de cinq d̀ sept jours.

L'administration de tetracaïne sous-arachnoïdienne a produit un bloc-moteur de $186 \pm 58$ (moyenne \pm SEM) min. La clonidine de même que l'épinéphrine ont produit une prolongation identique du bloc-moteur d la tetracaine, 135 pour cent $(p<0.01)$ et 116 pour cent $(p<$ 0.05) respectivement, comparativement a la tetracaïne seule. Aucun bloc-moteur n'a été observé avec la clonidine seule, l'épinéphrine, ou le cinq pour cent glucose dans l'eau, L'addition de clonidine d̀ la tetracaine pour une rachi-anesthésie a produit une augmentation significative dans la durée du bloc sensoriel, 56 pour cent $(p<0.01)$ et 107 pour cent $(p<0.01)$ respectivement, comparativement d̀ la tetracaïne avec ou sans épinéphrine. L'administration rachidienne de clonidine seule a produit un bloc sensoriel de $76 \pm 17$ minutes, alors qu'un seul chien ayant reçu de l'épinéphrine sous-arachnoüdienne a prêsenté un bloc sensoriel 140 minutes). Aucun déficit neurologique n'a été observé chez aucun de ces animaux.

Cette étude conclut que chez les chiens devant subir une rachi-anesthésie à la tetracaïne, la clonidine est aussi efficace que l'épinéphrine dans la prolongation du bloc-moteur et serait plus efficace dans la prolongation du bloc sensoriel. 